\title{
EDITORIAL
}

\section{Una epidemia durante 20 años}

"... ¿dónde estamos, pues? Vosotros, hombres de razón, tenéis que adivinarlo. Yo tengo formada mi opinión desde siempre, y estoy firme en mis principios: la vida equivale a la muerte; el hombre es la leña con que se hacen las hogueras. Creedme, os vais a poner en apuros."

El estado de sitio. Albert Camus.

E n junio y julio de 1981 se informaron los primeros casos de SIDA en los Estados Unidos de América $(\mathrm{EUA})^{1,2}$ y desde entonces, con una escalofriante precisión se han cumplido la mayoría de las predicciones epidemiológicas formuladas en su inicio. Hoy, el número de casos se acerca a un total acumulado de 40 millones en el mundo y la epidemia continúa rampante. Cada día se infectan 16 mil personas, la mayoría por transmisión sexual, y todas esas infecciones son potencialmente prevenibles. La dramática situación del África subsahariana, con países ya ahora devastados y con un futuro aún más oscuro, pronto será multiplicada por su crecimiento en la India y Asia en general. ${ }^{3} \mathrm{La}$ epidemia ha evolucionado de acuerdo a características económicas, sociales y culturales, y obviamente su contención ha sido factible en el mundo desarrollado (EUA, Canadá y Europa occidental) pero no ha tenido límite en la inmensa mayoría de países sin recursos económicos.

Conforme la epidemia ha transcurrido nuestro conocimiento ha crecido, y así se descubrieron los virus responsables (VIH 1 y 2), sus vías de transmisión y la eficiencia de cada una, los tratamientos útiles para prevenir y tratar algunas de las complicaciones más frecuentes, los medicamentos que actúan específicamente sobre el virus interrumpiendo su replicación con la mejoría consecuente de la inmunidad celular, las intervenciones eficaces para educar a grupos específicos, el escrutinio de la sangre y la alerta en cuanto a los usos comerciales de los derivados sanguíneos. Hoy, la reconstitución inmunológica es un objetivo cercano y los estudios para desarrollar una vacuna efectiva son intensos. Lo anterior se ha traducido en la disminución de muertes en todos aquellos países donde existe la opción de tratamiento, en la disminución de requerimientos de hospitalización, y en la impresionante eficacia de las combinaciones de antivirales que, junto con un manejo médico óptimo, permiten hoy una vida satisfactoria a individuos que hace apenas 10 años hubieran fallecido por no contar con los adelantos terapéuticos actuales.

Así, tenemos que ya existen magníficas opciones terapéuticas y conocemos efectivas intervenciones preventivas, pero en el mundo la infección sigue aumentando su paso porque el costo de su manejo es inalcanzable para la mayoría. Ante esto, ha resultado atractivo para algunos críticos señalar reiteradamente que sólo hay motivos de insatisfacción y desesperanza, con lo que no concuerdo. Como clínico no puedo dejar de alegrarme cada vez que recibo a un paciente que pudo haber fallecido hace 5 o 10 años, cada vez que testifico el logro, no esperable hace pocos años, de culminar estudios, formar relaciones, tener hijos o viajar por el mundo, o en pocas palabras, de vivir. Sin embargo, ciertamente el panorama mundial es desolador.

En México la epidemia inició en 1983 con el informe de los primeros casos. ${ }^{4,5}$ Es cierto que aun ahora hay pacientes sin acceso al tratamiento, es cierto que hay pacientes con tratamientos incorrectos, es cierto que hay discriminación. También es cierto que en este corto periodo hemos recorrido un largo camino y la evolución de la epidemia da cuenta de ello: nuestra tasa de infección es menor a la que tienen nuestros vecinos en norte y sur, ${ }^{6}$ el número de casos de infección perinatal disminuyó a eventos esporádicos, todas las mujeres tienen acceso a tratamiento y se buscan las condiciones para extenderlo a la totalidad de los pacientes, no hay más casos por transfusión de sangre, y 
su manejo hospitalario es respetuoso. Todos estos logros son consecuencia de la participación responsable del Estado, el sector salud y la sociedad civil. Ciertamente esto no debe dejar espacio para la complacencia sino estimular un mayor esfuerzo por obtener mejores resultados. Enfrentando ahora una epidemia concentrada deben incrementarse los recursos para campañas educativas con objetivos muy específicos. Intervenciones en diferentes niveles son urgentemente necesarias en parejas con riesgo, en pacientes con enfermedades de transmisión sexual y en el ámbito institucional. Las experiencias del ejército tailandés, del estudio en fábricas de Zimbabwe y las intervenciones muy dirigidas en escuelas de EUA, han tenido buenos resultados ${ }^{7}$ y es lo que tendríamos que implementar ahora. La información que hoy tenemos nos permitiría diseñar intervenciones a la medida para cada ciudad o región. No hacerlo así será mucho más costoso en un corto plazo.

De hecho, el momento de intervenir con más intensidad es óptimo ante dos situaciones concretas. Una es la reciente victoria de Sudáfrica frente a las compañías farmacéuticas para producir genéricos a un menor precio, situación similar a su producción por Brasil y la India, y la otra, es el cambio de política de precios de algunas compañías como ha sido logrado en México. Lo anterior permitirá a países como el nuestro aumentar significativamente la distribución de antivirales, y simultáneamente enfatizar los programas preventivos.

Pero a pesar de logros y desarrollos, la situación de la pandemia es terrible, y debería llevarnos a reflexionar sobre un orden mundial que permite, en el principio del tercer milenio y celebrando nuestra lectura del código genético, que la pobreza sea causa de la devastación de un continente y más. No es accidental la coincidencia de SIDA, Tuberculosis y Paludismo: la enfermedad sigue la ruta que marcan la pobreza y la ignorancia. La propuesta de la Organización Mundial de la Salud para la creación del fondo especial y la disminución de precios en algunos medicamentos, dejarán tranquilas algunas conciencias, pero es claro que no solucionan el problema en su origen. Necesitamos una organización económica diferente, que considere a la salud como un derecho universal y que lo convierta en realidad con presupuestos suficientes, porque de no ser así seguramente nos veremos en apuros todavía peores.

Samuel Ponce de León R.

\section{Referencias}

I. Pneumocystis pneumonia-Los Angeles. MMWR Morb Mortal Wkly Rep I98I Jun 5;30:250-252.

2. Kaposi's sarcoma and Pneumocystis pneumonia among homosexual men - New York City and California. MMWR Morb Mortal Wkly Rep I98I Jul 3;30:305-308.

3. Fauci AS. Infectious Diseases: Considerations for the 2 I st Century. Clin Infect Dis 200I;32:675-685.

4. Ruiz-Argüelles G, Ponce de León RS, Ruiz-Palacios G. El síndrome de inmunodeficiencia adquirida en México. Rev Invest Clin 1983;35:265-266. 5. Abud-Mendoza C,Alcocer-Varela J, González Amaro R, Díaz Jouanen E, Alarcón SD. Síndrome de inmunodeficiencia adquirida, datos clínicos e inmunológicos de nueve pacientes. Rev Invest Clin 1984;36:3 I I-319.

6. Magis-Rodríguez C, Bravo-García E, Rivera-Reyes P. El SIDA en México en el año 2000. Epidemiologia 200I; I al 7 de abril: I8(I4):I-3.

7. Coates TJ, Ehrdhart AA, Celentano DD. Human immunodeficiency virus prevention:Applying the lessons learned. En:Volverding P, Jacobson M, ed. AIDS Clinical review 2000/200I. Nueva York (NY): Marcel Decker Inc, 2001 .

\footnotetext{
* Subdirección de Epidemiología Hospitalaria y Control de Calidad de la Atención Médica. Instituto Nacional de Ciencias Médicas y Nutrición Salvador Zubirán. México, D.F., México.
} 